Syntax Literate : Jurnal Ilmiah Indonesia p-ISSN: 2541-0849

e-ISSN: 2548-1398

Vol. 5, No. 5 Mei 2020

\title{
ANALISA PAKAN BURUNG OTOMATIS MENGGUNAKAN ARDUINO BERBASIS INTERNET OF THINGS
}

\section{Arif Rakhman dan Rais}

Politeknik Harapan Bersama Tegal

Email : cakrakirana7@gmail.com dan raishojawa@gmail.com

\section{Abstract}

Technology is developing rapidly in today, along with the development of these technologies so there are impacts. Like Lovebird's feed, it is also a concern for some people to integrate it with technology, we also began looking for ideas to make automatic Lovebird's feed tools and also can monitor the condition of the availability of feed, automatic Lovebird's feed tool is very helpful for lovebird breeders. With this tool, Lovebird breeders do not worry about hunger and also the availability of feed. With twice one day scheduling system then daily lovebird eating needs can be fulfilled. From the explanation of the problem above then it is very appropriate if be made a title "Automatic Bird Feed Using Arduino Based on Internet of Things". This system is designed and built using Arduino Microcontroller technology as its automation, as well as using NodeMCU ESP8266 which acts as a web client, which can receive and send data to websites based PHP \& MySQL.

Keywords: Weighted Moving Averages, forcasting of pmi, bloodtype

\section{Abstrak}

Teknologi berkembang dengan pesat pada era sekarang, seiring perkembangan teknologi tersebut maka ada dampak yang ditimbulkan. Seperti pakan Burung Lovebird pun menjadi perhatian bagi sebagian orang untuk memadukannya dengan teknologi, dari itulah mulai mencari ide untuk membuat alat pakan burung Lovebird otomatis dan juga dapat memonitoring kondisi kesediaan pakannya, alat pakan burung Lovebird otomatis ini sangat membantu bagi para peternak lovebird. Dengan alat ini peternak burung Lovebird tidak khawatir akan kelaparan dan juga akan kesediaan pakannya. Dengan sistem penjadwalan sehari 2 kali maka kebutuhan makan lovebird sehari-hari dapat terpenuhi. Sistem ini dirancang dan dibangun dengan menggunakan teknologi Microcontroller Arduino sebagai otomatisasinya, serta menggunakan NodeMCU ESP8266 yang berperan sebagai web client, yang dapat menerima dan mengirim data ke website berbasis PHP \& MySQL. Hasil uji coba menunjukan bahwa sistem yang telah dibuat berjalan dengan baik. Sistem mampu membuka menutup pakan melalui kontrol dari web dan berjalan secara otomatis. Ketingginan pakan ditampilkan di LCD dan informasi 
mengenai ketinggian pakan, riwayat pemberian pakan dapat dilihat di web secara real time.

Kata kunci: Pakan burung otomatis, IoT, lovebird, Arduino, Microcontroller

\section{Pendahuluan}

Perkembangan teknologi yang semakin pesat mempengaruhi gaya hidup yang semakin mencolok. hidup di zaman globalisasi atau bisa juga disebut zaman modernisasi. Jika dulu manusia dalam berkomunikasi harus selalu bertatap muka, tetapi kini komunikasi terjadi tanpa ada batas ruang dan waktu (Abdurokhim, 2016). Modernisasi sendiri dalam ilmu sosial merujuk pada bentuk transformasi dari keadaan yang kurang maju atau kurang berkembang ke arah yang lebih baik dengan harapan kehidupan masyarakat akan menjadi lebih baik. Pada zaman modernisasi seperti sekarang, manusia sangat bergantung pada teknologi. Hal ini membuat teknologi menjadi kebutuhan dasar setiap orang, dari orang tua hingga anak muda, para ahli hingga orang awam pun menggunakan teknologi dalam berbagai aspek kehidupannya.

Hal itu berdampak apabila memiliki ternak burung saat ditinggalkan oleh sang pemilik burung tersebut juga membutuhkan makan seperti halnya manusia, sehingga membutuhkan suatu alat yang mampu membantu dalam hal tersebut sehingga ternak burung tidak mengalami kelaparan saat ditinggal pergi (Sunardi \& Artati, 2014).

Burung adalah hewan yang memiliki bulu dan sayap, jenis-jenis burung begitu bervariasi, mulai dari burung pemakan daging, pemakan serangga dan pemakan bijibijian, burung telah memberikan manfaat luar biasa dalam kehidupan manusia, beperapa jenis burung seperti murai batu yaitu burung yang indah suaranya, cucak hijau dan tentu juga burung lovebird (Sulistyo Aji \& Arifin, 2015).

Burung lovebird merupakan hewan yang mempunyai sifat yang setia pada pasanganya dan terbiasa hidup berkelompok atau berkoloni, burung lovebird mempunyai banyak jenis warna/genetic mulai dari burung love bird pastel hijau,burung lovebird pastel kuning, burung lovebird olive, burung lovebird batman dan masih banyak jenis lainnya.

Burung lovebird merupakan burung pemakan biji-bijian, seperti millet dan sayur-sayuran seperti jagung, kangkung, biasanya para peternak burung lovebird memberi makan dua kali sehari pagi dan sore hari, karena kalau diberi makan sekaligus atau satu kali dalam sehari bisa diacak-acak oleh burung lovebird hal ini akan membuat pemborosan pada makanan, agar burung lovebird dapat makan secara teratur dan dapat membangun nafsu makannya (Alfatah \& Bambang Hari, 2016).

Sistem ini di buat untuk mempermudah pemilik ternak burung lovebird dalam hal pemberian makan sehingga pemilik tidak lagi khawatir terlambat memberi makan sehingga burung lovebird tidak kelaparan. Sistem ini bekerja secara otomatis yang sudah di atur dengan cara penjadwalan yg di tentukan sesuai dengan kebutuhan. 


\section{Metode penelitian}

Rencana merupakan tahap awal dalam melakukan penelitian untuk menyusun langkah apa saja yang akan dilakukan dan yang akan dibuat selanjutnya. Tahap awal ini menjadi landasan sebelum melakukan analisis, rencana, dan implementasi. Setelah dilakukannya observasi pada peternak burung lovebird Bapak Wangsa, maka dibuatlah sebuah sistem kontrol pemberian pakan burung lovebird secara otomatis.

Analisis berisi langkah-langkah awal mengumpulkan data, penyusunan dan penganalisaan hingga dibutuhkan untuk menghasilkan produk. Melakukan analisa permasalahan yang dialami peternak burung lovebird dalam proses monitoring kesedian pakan. Adapun data yang digunakan dalam rancang bangun sistem pakan burung otomatis menggunakan arduio berbasis internet of things ini adalah data primer dan data sekunder. Data primer yaitu data yang diperoleh peneliti secara langsung dari sumber aslinya dengan cara observasi, wawancara maupun studi pustaka guna untuk menyelesaikan permasalahan yang sedang ditangani. Data sekunder adalah data yang diperoleh peneliti dari sumber yang sudah ada.

Rancangan atau desain merupakan tahap pengembangan setelah analisis dilakukan. Rancang bangun sistem sistem pakan burung otomatis menggunakan arduio berbasis internet of things menggunakan flowchart untuk alur kerja alat dan UML untuk membangun sistem informasinya. Terdapat rangkaian perangkat keras dan desain input atau output yang akan digunakan.

Implementasi hasil dari penelitian ini akan diuji coba secara real dalam bentuk prototype untuk menilai seberapa baik sistem sistem pakan burung otomatis menggunakan arduio berbasis internet of things yang telah dibuat. Memperbaiki bila ada kesalahan-kesalahan yang terjadi, kemudian hasil dari uji coba tersebut akan diimplementasikan sebagai pemodelan rancang bangun sistem sistem pakan burung otomatis menggunakan arduio berbasis internet of things.

\section{Hasil Dan Pembahasan}

Gambaran umum perancangan sistem yang akan dibuat pertama Mikrokontroler melakukan autentikasi Wi-Fi, motor akan dikontrol sesuai inputan dari halaman web kontrol. Perancangan sistem berikutnya berjalan secara otomatis Sensor Ultrasonik HCSR04 membaca ketinggian pakan, kemudian LCD akan menampilkan informasi jam dan tanggal. Hasil dari pembacaan ketinggian pakan dikirim ke database, kemudian ditampilkan di web secara real time beserta informasi yang lebih lengkap. Perancangan sistem yang lebih spesifik akan digambarkan dalam bentuk Flowchart, Use Case Diagram, Activity Diagram, Sequence Diagram dan Class Diagram. 
1. Flowchart

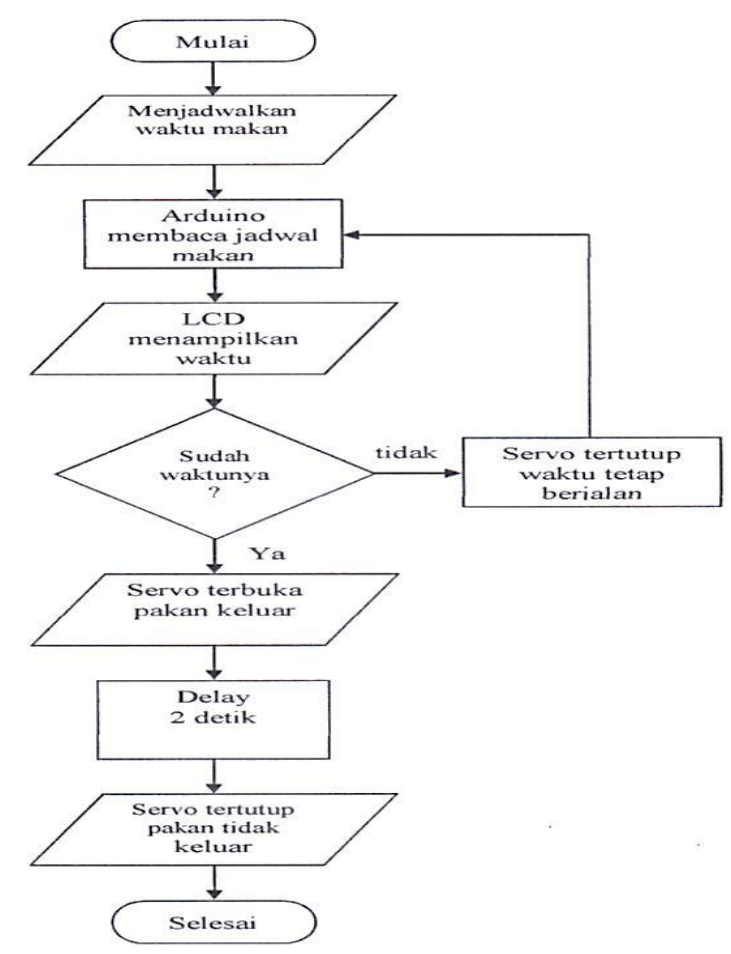

Gambar 1 Flowchart Pakan Burung Otomatis Menggunakan Arduino Berbasis IoT

2. Use Case Diagram

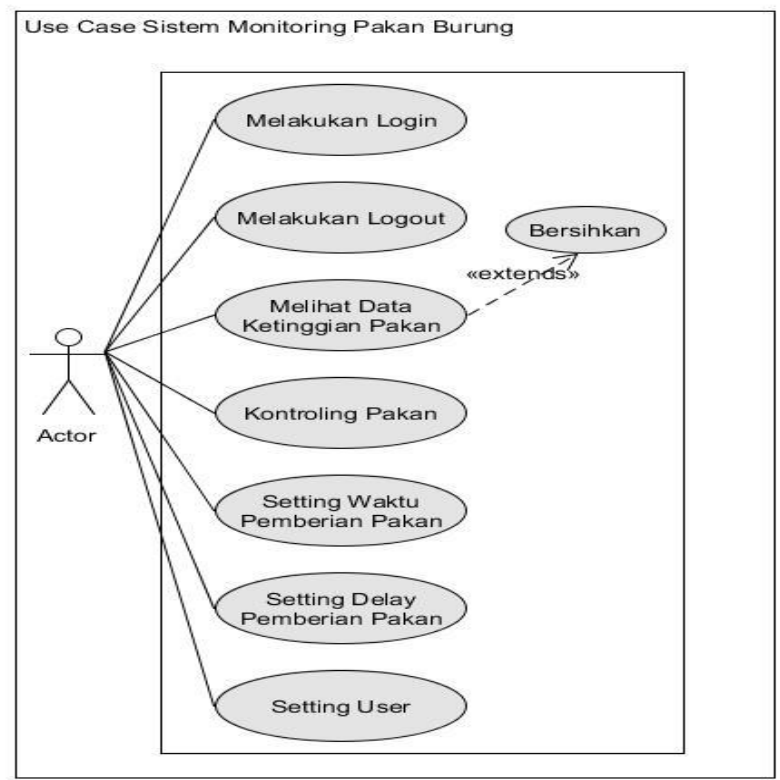

Gambar 2 Use Case Diagram Pakan Burung Otomatis Menggunakan Arduino Berbasis Internet of Thing 
Arif Rakhman dan Rais

3. Rangkaian Perangkat Keras

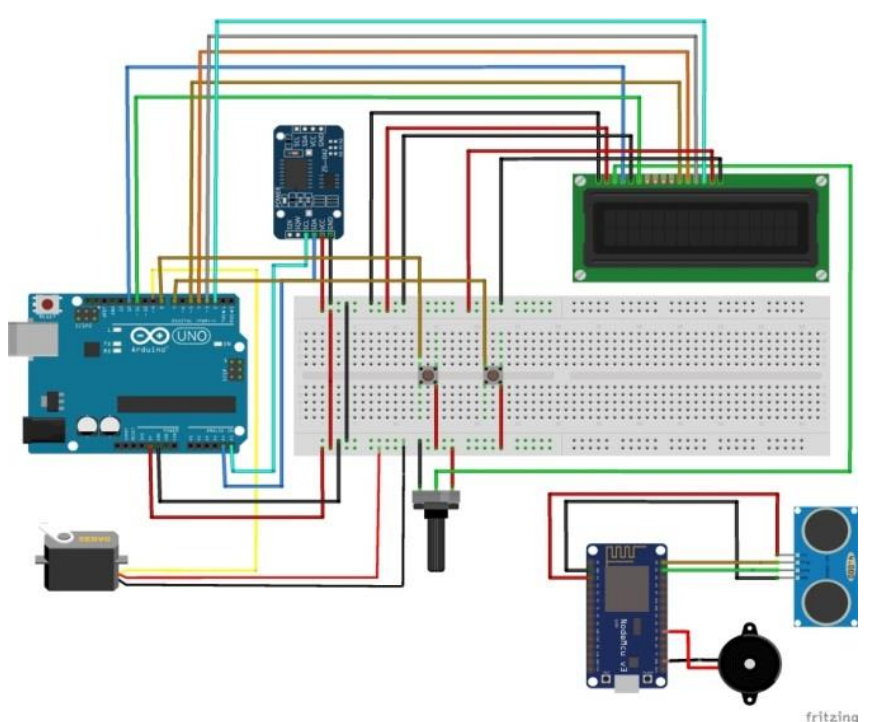

Gambar 3 Rangkaian Pakan Burung Otomatis Menggunakan Arduino Berbasis Internet of Things

Tahap implementasi merupakan tahap penerapan sistem kontrol ke objek yang telah dirancang, dalam hal ini sistem dapat membuka dan menutup motor servo melalui kontrol dari web dan berjalan secara otomatis serta informasi mengenai ketinggian pakan yang dapat dilihat di web secara real time.

1. Implementasi Perangkat Keras

Instalasi perangkat keras merupakan suatu proses instalasi alat atau perakitan alat yang digunakan dalam sistem pakan burung otomatis menggunakan arduino berbasis internet of things (Saberan, Asyikin, Putra, Saputro, \& Wahyudi, 2018).

Adapun minimal perangkat keras yang digunakan untuk memenuhi kriteria dalam pengoperasian objek sebagai berikut: Wemos D1 R1
a. Arduino Uno
b. NodeMCU esp8266
c. Sensor Ultrasonik HC-SR04
d. LCD i2c 16x2
e. Motor Servo
f. buzzer
g. RTC
h. Kabel jumper
i. Pus Button
j. Breadboard
k. Baut ulir diameter $8 \mathrm{~mm}$
1. Akrilik tebal $2 \mathrm{~mm}$ 
2. Implementasi Perangkat Lunak

Adapun perangkat lunak yang dapat digunakan untuk mengimplementasikan sistem ini adalah sebagai berikut:
a. Arduino IDE
b. Web Browser

\section{A. Hasil Pengujian Perangkat Keras}

Pengujian otomatisasi Pakan Burung merupakan tahap pertama yang harus dilakukan. Dimana pengujian dilakukan dengan melakukan uji pembukaan dan penutupan servo. Untuk membuka servo diatur pada pukul 06.00 dan 17.00. Jika waktu menunjukan pukul 06.03 atau pukul 17.03 maka servo akan kembali tertutup.

Tabel 1 Hasil Pengujian Perangkat Keras Pakan Burung Membuka Secara Otomatis

\begin{tabular}{cccl}
\hline Waktu pada LCD & Yang diharapkan & Pengamatan & \multicolumn{1}{c}{ Kesimpulan } \\
\hline Pukul 05.59 & Pakan tidak keluar & Posisi Servo $0^{\circ}$ & $\begin{array}{l}{[\sqrt{ }] \text { Diterima }} \\
{[-] \text { Tidak Diterima }}\end{array}$ \\
\hline Pukul 06.00 & Pakan keluar & Servo memutar 20 & $\begin{array}{l}{[\sqrt{ }] \text { Diterima }} \\
{[-] \text { Tidak Diterima }}\end{array}$ \\
\hline Pukul 06.01 & Pakan tidak keluar & $\begin{array}{c}\text { Servo kembali ke } \\
0^{\circ}\end{array}$ & $\begin{array}{l}{[\sqrt{ }] \text { Diterima }} \\
{[-] \text { Tidak Diterima }}\end{array}$ \\
\hline Pukul 16.59 & Pakan tidak keluar & Posisi Servo $0^{\circ}$ & $\begin{array}{l}{[\sqrt{ }] \text { Diterima }} \\
{[-] \text { Tidak Diterima }}\end{array}$ \\
\hline Pukul 17.00 & Pakan keluar & Servo memutar 20 & $\begin{array}{l}{[\sqrt{ }] \text { Diterima }} \\
{[-] \text { Tidak Diterima }}\end{array}$ \\
\hline Pukul 17.02 & Pakan tidak keluar & $\begin{array}{c}\text { Servo kembali ke } \\
0^{\circ}\end{array}$ & $\begin{array}{l}{[\sqrt{ }] \text { Diterima }} \\
{[-] \text { Tidak Diterima }}\end{array}$ \\
\hline
\end{tabular}

\section{B. Hasil Pengujian Perangkat Lunak}

Sesuai pengujian metode black box pada tabel diatas maka disimpulkan pada posisi awal servo yaitu $0^{\circ}$, jika pukul 06.00 dan 17.00 maka servo memutar $20^{\circ}$ (pakan keluar), jika pukul 06.03 dan 17.03 maka servo kembali memutar $0^{\circ}$ (pakan tidak keluar). Kemudian pada pengujian monitoringnya, jika pukul 05.59 dengan ketinggian awal $8 \mathrm{~cm}$, maka pukul 06.00 pakan keluar dan ketinggian pakan berkurang menjadi $6 \mathrm{~cm}$, data tersebut akan ditampilkan pada website Pakan Burung.

Tabel 2 Hasil Pengujian Perangkat Keras Pintu Air Menutup Secara Otomatis

\begin{tabular}{cccll}
\hline Pukul & $\begin{array}{c}\text { Yang } \\
\text { diharapkan }\end{array}$ & $\begin{array}{c}\text { Pembacaan } \\
\text { Sensor }\end{array}$ & $\begin{array}{c}\text { Pengamatan web Pakan } \\
\text { Burung }\end{array}$ & \multicolumn{1}{c}{ kesimpulan } \\
\hline 05.59 & $\begin{array}{c}\text { Pakan belum } \\
\text { berkurang }\end{array}$ & Aktif & $\begin{array}{l}\text { Menampilkan } \\
\text { ketinggian pakan } 8 \mathrm{~cm}\end{array}$ & $\begin{array}{l}{[\sqrt{ }] \text { Diterima }} \\
{[-] \text { Tidak Diterima }}\end{array}$ \\
\hline 06.00 & $\begin{array}{c}\text { Pakan } \\
\text { berkurang }\end{array}$ & Aktif & $\begin{array}{l}\text { Menampilkan } \\
\text { ketinggian pakan } 6 \mathrm{~cm}\end{array}$ & $\begin{array}{l}{[\sqrt{ }] \text { Diterima }} \\
{[-] \text { Tidak Diterima }}\end{array}$ \\
\hline \multirow{2}{*}{16.59} & $\begin{array}{c}\text { Pakan belum } \\
\text { berkurang }\end{array}$ & Aktif & $\begin{array}{l}\text { Menampilkan } \\
\text { ketinggian pakan } 6 \mathrm{~cm}\end{array}$ & $\begin{array}{l}{[\sqrt{ }] \text { Diterima }} \\
{[-] \text { Tidak Diterima }}\end{array}$ \\
\hline
\end{tabular}




\begin{tabular}{lllll}
\hline 17.00 & $\begin{array}{c}\text { Pakan } \\
\text { berkurang }\end{array}$ & \multirow{2}{*}{ Aktif } & $\begin{array}{l}\text { Menampilkan } \\
\text { ketinggian pakan } 4 \mathrm{~cm}\end{array}$ & $\begin{array}{l}{[\sqrt{ }] \text { Diterima }} \\
{[-] \text { Tidak Diterima }}\end{array}$ \\
\hline
\end{tabular}

\section{Hasil Produk}

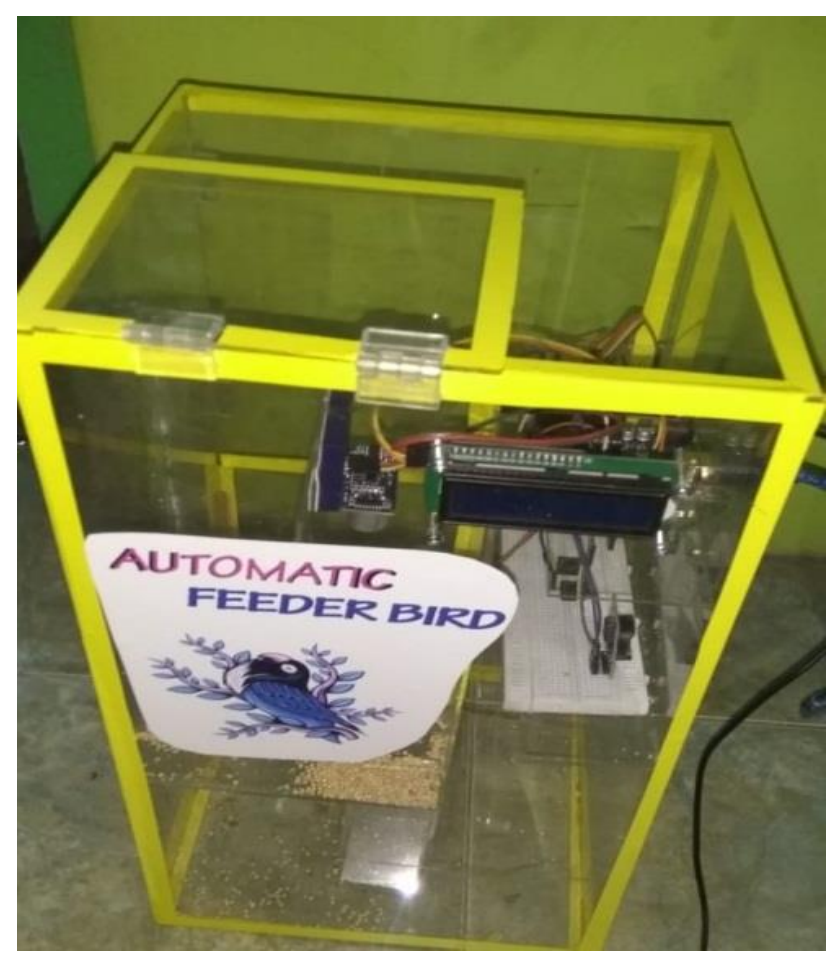

\section{Gambar 4 Prototype Pakan Burung Otomatis Menggunkan Arduino Berbasis Internet of Things}

\section{Kesimpulan}

Adapun kesimpulan dari pembuatan rancang bangun sistem Pakan Burung Otomatis Menggunkan Arduino Berbasis Internet of Things dapat diimplementasikan secara real dalam bentuk prototype. Hasil uji coba menunjukan bahwa sistem yang telah dibuat berjalan dengan baik. Sistem mampu membuka menutup pakan melalui kontrol dari web dan berjalan secara otomatis. Ketingginan pakan ditampilkan di LCD dan informasi mengenai ketinggian pakan, riwayat pemberian pakan dapat dilihat di web secara real time. 


\section{BIBLIOGRAFI}

Abdurokhim, Abdurokhim. (2016). Analisis Komparatif Penggunaan Sistem Informasi Perbankan antara Bank Syariah aan Bank Konvensional. Syntax Literate; Jurnal Ilmiah Indonesia, 1(1), 41-54.

Alfatah, Muhammad Rosyid, \& Bambang Hari, P. (2016). Prototype Sistem Buka Tutup Otomatis Pada Pintu Air Bendungan Untuk Mengatur Ketinggian Air Berbasis Arduino. Universitas Muhammadiyah Surakarta.

Saberan, Saberan, Asyikin, Arifin Noor, Putra, Aditiya Areza, Saputro, Ahmad Kukuh Aji, \& Wahyudi, Rahim. (2018). Rancang Bangun Prototipe Buka Tutup Pintu Bendungan Otomatis Berbasis IoT Menggunakan SMS Gateway. Poros Teknik, 10(1), 18-24.

Sulistyo Aji, M. Catur, \& Arifin, Zaenal. (2015). Rancang Bangun Pintu Air Berbasis Mikrokontroler Atmega16. Diponegoro University.

Sunardi, Sunardi, \& Artati, Rara Sri. (2014). Aplikasi Metode Fuzzy Sugeno untuk Sistem Informasi Ketinggian Air dan Ketinggian Pintu Air suatu Bendungan. Dinamik, 19(2). 